\title{
EFEITO DE INTERVENÇÃO VIA CUIDADORES SOBRE AQUISIÇÃO DE TATO COM AUTOCLÍTICO EM CRIANÇAS COM TEA
}

\section{EFFECT OF INTERVENTION VIA CAREGIVERS ON ACQUISITION OF TACT WITH AUTOCLITICS IN} CHILDREN WITH ASD

MARILU MicheLLy CRUZ DE Borba

Patricia Caroline Madeira Monteiro

ADRIANO ALVES BARBOZA

EDUARDO NASCIMENTO TRINDADE

ROMARIZ DA SILVA BARROS

\author{
UNIVERSIDADE FEDERAL do PARÁ, BRASIL E \\ INSTITUTO NACIONAL DE CIÊNCIA E TECNOLOGIA SOBRE COMPORTAMENTO, COGNIÇÃO E ENSINO, BRASIL
}

\section{RESUMO}

A efetividade da intervenção analítico-comportamental implementada via cuidadores de crianças diagnosticadas com Transtorno do Espectro do Autismo (TEA) foi avaliada em contexto aplicado com três famílias do norte do Brasil. Foram ensinados repertórios de tato com autoclítico. Participaram três crianças diagnosticadas com TEA (e seus respectivos cuidadores), dois meninos (4 e 5 anos de idade) e uma menina (6 anos). As crianças já haviam aprendido repertório de tato. Os cuidadores foram ensinados a implementar procedimentos de intervenção usando Ensino por Tentativas Discretas (Discrete Trial Teaching, DTT). Após esse treino, os cuidadores passaram a ser supervisionados semanalmente. Todas as crianças registraram $0 \%$ de precisão de desempenho de tato com autoclíticos na linha de base. A percentagem foi próxima de $100 \%$ no passo final da intervenção implementada pelos cuidadores. A manutenção do repertório Foi também avaliada em uma sessão de follow-up um mês após o ensino. Uma criança mostrou $100 \%$ de manutenção e as outras duas mostraram manutenção parcial. Os dados mostraram que a intervenção via cuidadores é uma forma promissora de dar amplo acesso a intervenção analítico-comportamental ao autismo no Brasil.

Palavra-chave: tato, autoclítico, intervenção via cuidadores, autismo.

\section{ABSTRACT}

The effectiviness of a behavior-analytic intervention implemented via caregivers of children diagnosed with autism spectrum disorder (ASD) was evaluated in an applied context with three families in Northern Brazil. We taught tact with auticlitic repertoire. Three children diagnosed with ASD (and their respective caregivers) participated (one 6year-old girl and two boys, 4 and 5 years old). The children were already taught tact repertoire. Caregivers were given training to implement intervention procedures using Discrete Trial Teaching (DTT). After that, caregivers were given systematic supervison once a week. All the children showed $0 \%$ of accuracy in tact with auticlitic performance during baseline measurement. The percetage was close to $100 \%$ of accuracy on the final step of the intervention implemented by the caregivers. The maintenance of the repertoire was also evaluated in a follow-up session carried-out a month after. One child showed 100\% maintenance and other two children partial maintenance. The data showed that caregiver-based approach is a promissing way to give comprehensive access to behavior-analytic intervention to children diagnosed with autism in Brazil.

Keywords: tact, autoclitic, caregiver-based intervention, autism.

Correspondência para Marilu Borba, marilucruz@gmail.com, ou Romariz Barros, romarizsb@gmail.com. Trabalho baseado na Tese de Doutoramento da primeira autora, sob supervisão do último autor. A segunda autora é bolsista CAPES, o terceiro autor é bolsista CNPq e o último autor é bolsista de produtividade do CNPq, Nível 2. O trabalho contou com financiamento do CNPq (processos 306349/2012-4 e 409139/2013-0) do INCT-ECCE (processo no 573972/2008-7). 
De acordo com o DSM V (APA, 2013), os casos de Transtornos do Espectro do Autismo (TEA) são caracterizados pelo déficit de comunicação e interação social, sendo observada a presença de padrões restritos e repetitivos de comportamentos, interesses e atividades. Os primeiros sinais aparecem ainda na primeira infância e os déficits prejudicam, de forma ampla, diferentes âmbitos da vida da criança.

A Análise Aplicada do Comportamento tem obtido bons resultados na intervenção ao TEA (Cohen, Amerine-Dickens, \& Smith, 2006; Eikeseth, Klintwall, Jahr, \& Karlsson, 2012; Eikeseth, Smith, Jahr, \& Eldevik, 2002; Eldevik, Hastings, Jahr, \& Hughes, 2012; Lovaas, 2003; Sallows \& Graupner, 2005; Smith, Eikeseth, Klevstrand, \& Lovaas, 1997). Esses resultados, em geral, decorrem de formas de intervenção analíticocomportamentais que sejam intensivas (pelo menos 20 horas semanais), duradouras (por volta de dois anos) e precoces (iniciando cedo na vida da criança), conduzidas de forma individualizada por profissional habilitado (Lovaas, 1987). Entretanto, essas características (intervenção individualizada, intensiva e duradoura) determinam que o tratamento seja oneroso e de difícil acesso à maior parte da população.

Neste sentido, a intervenção indireta (ou intervenção via cuidadores) desponta como uma alternativa viável em termos de custos. A intervenção indireta se caracteriza pela ênfase no treinamento de cuidadores para auxiliar na intensidade da aplicação dos programas de ensino, formulados conforme criteriosa avaliação do caso.

Esse tipo de intervenção é organizado de forma que os cuidadores são orientados a realizar procedimentos de ensino com a criança, conforme o planejamento do analista do comportamento. Após o treino, na maioria dos estudos, os cuidadores passam a receber orientação profissional periódica e regular (cf. Gillett \& LeBlanc, 2007; Matson, et al., 2009; Sallows \& Graupner, 2005; Smith, Buch, \& Gamby, 2000).

Extensa pesquisa sobre a efetividade da intervenção indireta (e sobre seus pontos fortes e fracos) ainda precisa ser realizada no contexto sócio-cultural brasileiro e, em especial, do norte do Brasil, onde uma parcela maior da população está dentro de faixas sócioeconômicas mais baixas. Iniciativas nesse sentido se intensificaram recentemente (Borba, 2014; Faggiani, 2014). Mesmo internacionalmente, a intervenção via cuidadores ainda é pouco investigada. Uma revisão feita por Wolery e Garfinkle (2002) sobre a intervenção comportamental mostrou que apenas sete dos 72 estudos analisados foram realizados via cuidadores. McConachie, Philp e Diggle (2007), por sua vez, realizaram uma revisão apenas dos trabalhos de intervenção via cuidadores e encontraram poucos estudos na área. Além disso, apesar de esses estudos sugerirem a melhora da criança em áreas como a comunicação, há poucas pesquisas comprovando essa informação por meio de evidências empíricas.

Entre os repertórios ensinados às crianças com TEA, o ensino de comportamentos verbais é um dos mais importantes, tanto por estarem correlacionados com os melhores prognósticos para a vida adulta (Kaplan \& Sadock, 2007), quanto por envolverem um repertório esperado pelos pais e pela sociedade, facilitando a interação e inclusão da criança.

O ensino de repertório verbal via cuidadores pode ser realizado por diferentes métodos, como o Paradigma da Linguagem Natural (e.g. Gillett \& LeBlanc, 2007), ensino incidental (e.g. Hsieh et al., 2011) e por tentativa discreta. $\mathrm{O}$ ensino por tentativa discreta é uma das formas mais comumente usadas no treinamento de crianças com autismo via profissional (Lafasakis \& Sturmey, 2007; Matson et al., 2009). Nessa estratégia de ensino, cada habilidade é ensinada por meio de um programa estruturado e dividido em passos, que aumentam gradativamente de complexidade, de acordo com o desempenho da criança. A tentativa discreta pode facilitar o ensino de diversas habilidades, como as sociais, acadêmicas e de linguagem.

$\mathrm{O}$ ensino de pais para o uso de tentativa discreta foi investigado, por exemplo, por Lafasakis e Sturmey (2007). Eles ensinaram três pais de crianças com autismo a aplicarem um programa de imitação, por tentativa discreta. O objetivo foi avaliar a aprendizagem dos pais, a generalidade do repertório aprendido pelos cuidadores para novos programas e a aprendizagem da criança. Os resultados foram positivos para os três objetivos.

Outro estudo que usou tentativa discreta foi realizado por Crockett et al. (2007). Duas mães foram ensinadas a realizar tentativa discreta com suas respectivas crianças. Para uma das crianças, foram ensinados os repertórios de atender ao nome, tato, brincar com bola e ecóico. Para outra criança, foram ensinados os repertórios de atender ao nome, escrever, contar e escolher. Os resultados mostraram que os cuidadores aprenderam a usar a tentativa discreta corretamente. Entretanto, os ganhos para as crianças foram leves, não havendo melhorias no repertório de tato. Os pesquisadores atribuem isso ao fato de as crianças terem sido expostas a apenas quatro ou seis sessões de treino.

Smith et al. (2000) investigaram a intervenção via cuidadores, com o uso de tentativa discreta em um procedimento em que os pais recebiam orientação sistemática de um profissional. Os dados mostraram que, nos cinco primeiros meses, cinco das seis crianças estudadas apresentaram ganhos nas áreas da linguagem receptiva, imitação verbal e imitação não verbal. Entretanto, os testes de follow-up, cerca de dois a três anos após o ensino, demonstraram manutenção das habilidades para apenas duas crianças. Os pesquisadores não tiveram controle sobre as contingências às quais as crianças foram expostas nesse longo período até o follow-up. Além disso, os pais aprenderam a usar o procedimento de tentativa discreta, porém sem a precisão de um profissional. Os pesquisadores sugerem que a intervenção via profissional poderia ser mais efetiva que o ensino via cuidadores.

A eficácia da intervenção ao autismo via cuidadores no Brasil ainda precisa ser investigada em todos os seus aspectos. É possível que essa forma de 
estruturar a intervenção seja muito importante para a ampliação do acesso da população à intervenção ao autismo no Brasil. A intervenção via cuidadores pode, ainda, ser muito adequada para gerar ganhos em todas as áreas de déficits da população afetada, entre elas o desenvolvimento de repertório verbal, que é central para reverter os principais sinais do quadro de TEA. A criança com diagnóstico de TEA frequentemente tenta mobilizar mecanicamente seus cuidadores de forma a obter reforçadores ou remover estimulação aversiva. Com o tempo, a manutenção dessas formas não verbais de interação com os outros, aliadas ao baixo interesse por interações sociais, determinam um repertório social e verbal muito abaixo do esperado para uma criança com desenvolvimento típico.

Crianças com desenvolvimento típico frequentemente mobilizam seus cuidadores através de interações verbais. O comportamento verbal (Skinner, 1957/1992) é comportamento operante mantido por consequências providas por um ouvinte, membro de uma comunidade verbal e por ela treinado para fazê-lo. Skinner (1957/1992), com base nas funções desses operantes verbais, apontou diversas categorias: Mando (solicitações), Tato (nomeação), Ecóico (reprodução de estímulo vocal), etc.

Dentre os operantes verbais básicos, o Tato é um dos mais importantes. Ele é um repertório de nomeação de estímulos ou de suas propriedades. Numa interação verbal caracterizada como Tato, o estímulo controlador (discriminativo) é não-verbal. A resposta é de nomear o estímulo (Brino \& Souza, 2005; Skinner, 1957/1992). A consequência reforçadora é social.

Considerando que o Tato é mantido por reforçamento social generalizado, crianças com autismo podem apresentar baixa sensibilidade a este tipo de reforçamento e seu ensino pode ser difícil. Além disso, diferente do Mando - que ocorre no contexto da motivação da criança para obter acesso a algo - os estímulos usados no ensino do Tato podem ser irrelevantes para a criança (Sundberg, Endicott, \& Eigenherr, 2000). É por isso que alguns autores apontam a importância das operações motivadoras para a aprendizagem deste repertório (e.g. Davis, Kahng, \& Coryat, 2012). A aprendizagem do Tato pode estar relacionada, dentre outras coisas, com o aumento de vocalização apropriada e diminuição de estereotipias vocais (Guzinski, Cihon, \& Eshleman, 2012).

$\mathrm{O}$ ensino do repertório de tato pode ser realizado com diferentes procedimentos de ajuda, como com a introdução de uma dica intraverbal (“o que é isso?"); uma dica textual; dica ecoica; e até com linguagem de sinais (Sundberg et al., 2000; Valentino \& Shillingsburg, 2011). Além disso, alguns estudos têm investigado a emissão de tato a partir do ensino conjunto deste com os repertórios de mando e ecoico (e.g., Kodak \& Clements, 2009) e ainda investigando a transferência de função entre os repertórios de mando e tato (e.g., Finn, Miguel, \& Ahearn, 2012).

A adequação do repertório de tato a situações sociais está relacionada com o seu uso em conjunto com respostas autoclíticas, que modulam e modificam esses tatos ou outros operantes verbais. O repertório verbal autoclítico consiste em respostas verbais controladas por aspectos do próprio comportamento verbal do falante e que alteram o efeito desse comportamento sobre o ouvinte. Por exemplo, a ocorrência de tatos com autoclíticos aumenta a efetividade da interação verbal de tato, ou seja, tornando mais provável o reforçamento daquela resposta por parte do comportamento do ouvinte.

Embora seja amplamente investigado na intervenção via profissionais, o ensino de repertórios verbais, em especial o tato com autoclítico, ainda é pouco explorado em uma intervenção via cuidadores. Desta forma, o objetivo deste trabalho foi propor e avaliar um programa de ensino de tato com autoclítico para crianças com diagnóstico de autismo, realizador por seus cuidadores, e investigar a manutenção desse ensino, com o cuidador e com outras pessoas, após um mês sem intervenção. As crianças foram ensinadas a nomear objetos do seu cotidiano, como o nome de seus brinquedos, com um procedimento de tentativa discreta em que era fornecida Dica Modelo Vocal (DMV) ${ }^{1}$, sem e com atraso.

\section{Participantes}

\section{MÉTODO}

Participaram do estudo três crianças, dois meninos e uma menina, com diagnóstico de TEA e seus respectivos cuidadores. Vítor (5 anos) e sua mãe Vitória (43 anos); Haroldo (4 anos) e sua mãe Heloísa (26 anos) e Luna (6 anos) e seus pais Lucas (46 anos) e Lúcia (42 anos). Todos os cuidadores haviam concluído pelo menos o Ensino Médio. Todas as crianças apresentavam repertório de ecoico, além de emitirem algumas variedades de mando e tato, mas não apresentavam repertório de tato com autoclítico.

Ao mesmo tempo em que o programa de tato com autoclítico foi aplicado, outros repertórios foram ensinados para as crianças: como mando com autoclitico, responder informações pessoais e seguimento de instrução.

Vítor, Haroldo e Luna realizavam os programas verbais de: "mando com autoclítico", "mando e intraverbal de sim/não", “intraverbal sim/não" e "informações pessoais".

Luna realizava os programas de: "atender ao nome" e "imitação com objeto".

Os estímulos usados no ensino do repertório de tato com autoclítico eram diferentes dos estímulos ensinados nos demais programas, de modo a diminuir a possibilidade de uma transferência de função. Porém, não foi realizado controle dos efeitos do ensino isolado do tato com autoclítico ou concomitante com o ensino de outros operantes verbais.

\footnotetext{
${ }^{1}$ Embora boa parte da literatura mencione o termo "dica ecoica", optamos por usar o termo "dica modelo vocal" (DMV) por ser mais preciso, uma vez que a dica em si não é ecoica, mas sim a resposta à dica modelo vocal, quando ocorre é que é uma resposta ecoica.
} 
O presente trabalho foi aprovado pelo Comitê de Ética em Pesquisa do Instituto de Ciências da Saúde da UFPA, conforme o parecer no. 175.303 de 14/12/2012, em consonância com a Resolução 196/96 do CNS/MS.

\section{Ambiente}

Os dados foram coletados pelos cuidadores, uma vez por semana nas instalações de do Núcleo de Teoria e Pesquisa do Comportamento da Universidade Federal do Pará, no âmbito do Projeto APRENDE (Atendimento e Pesquisa sobre Aprendizagem e Desenvolvimento). A sala de atendimento continha cinco mesas e 16 cadeiras infantis, dois armários e brinquedos dentro dos armários. Também foi realizada coleta de dados, no mínimo quatro vezes por semana, na casa dos participantes e com registro dos próprios cuidadores.

\section{Ensino de Cuidadores}

Os cuidadores haviam passado por um programa de Ensino de Cuidadores no qual tiveram cerca de 32 horas de ensino dos princípios básicos da Análise do Comportamento, por meio do método Keller (1999), incluindo 16 a 20 horas de ensino de aplicação de programas. Nesta fase, eram realizadas as seguintes atividades: leitura dos programas, análise de vídeos com a aplicação, demonstrações dos programas entre monitores, role-playing do cuidador com um monitor, demonstração do monitor com a criança e tentativa supervisionada do cuidador com a criança. Eles já haviam, no momento da presente pesquisa, aplicado cerca de oito programas pré-requisitos para as suas crianças ("atender ao nome", "atenção ao estímulo", "imitação com objeto", "imitação sem objeto", "sentar", "esperar", "toque aqui" e "rastreamento visual"), além de programas de mando e de tato sem autoclíticos.

Os cuidadores eram sistematicamente treinados a registrar os dados decorrentes da aplicação dos programas. Eles preenchiam folhas de registro entregues pelos experimentadores nas reuniões semanais. Ao final de uma semana, eles retornavam para a sessão de supervisão trazendo os dados. Uma sessão de aplicação do programa era realizada e filmada durante a sessão de supervisão, de forma que a confiabilidade dos dados trazidos de casa era verificada. Em nenhum caso foi encontrada discrepância entre os valores trazidos nas folhas de registro das sessões feitas em casa e aqueles valores obtidos nas sessões no laboratório.

\section{Teste de Preferência}

Antes de iniciar a sessão, era realizado um teste de preferência por meio do Multiple Stimulus Without Replacement, MSWO (Carr, Nicholson, \& Higbee, 2000; DeLeon \& Iwata, 1996). Neste teste, cinco brinquedos (ou comestíveis) eram apresentados ao mesmo tempo em uma mesa, e a criança era instruída a escolher um. Ela interagia por cerca de dez segundos com o item escolhido e era registrado que aquele havia sido o primeiro item de preferência. Após esse período, era solicitado que a criança escolhesse outro brinquedo entre os quatro restantes e novamente era registrado que aquele havia sido o segundo item de preferência. Isso era repetido até que restasse apenas um brinquedo. Todos os cinco itens eram então reapresentados, reiniciando o procedimento por mais duas vezes. Os três brinquedos registrados como tendo maior preferência eram selecionados para serem utilizados como reforçadores. Caso a criança demonstrasse interesse por outro item que não havia sido selecionado para o programa, este era imediatamente inserido nas tentativas da criança. Ressalta-se que os brinquedos selecionados no teste de preferência não eram utilizados para compor o conjunto de estímulos que seriam tateados, mas sim para serem utilizados como reforçadores.

\section{Linha de Base}

A linha de base foi realizada no laboratório com a apresentação de um conjunto de cinco estímulos. O procedimento foi realizado através de teste dos passos, de trás para frente, a partir do Passo 3. O pesquisador apresentou um brinquedo ou item familiar para criança como um vestuário, e aguardava $5 \mathrm{~s}$ pela vocalização (passo 3). Se não houvesse resposta o pesquisador mostrava um novo estímulo, aguardava $3 \mathrm{~s}$ e dava uma ajuda vocal (passo 2). Caso a criança não respondesse ou respondesse com erro iniciava-se o programa do Passo 1. Não havia consequência para acertos ou erros, respostas fáceis eram solicitadas e reforçadas a cada três tentativas aproximadamente. Cada alvo foi testado cinco vezes. A partir deste resultado, o cuidador era orientado sobre em que passo iniciar o ensino em casa.

\section{Programa}

Luna e Vítor foram ensinados a realizar tato com autoclítico de dois conjuntos de cinco estímulos distintos entre si. Haroldo foi ensinado a tatear três conjuntos com cinco estímulos em cada. Os estímulos utilizados em cada conjunto variaram de criança para criança, uma vez que os pais selecionavam brinquedos que eles tinham em casa.

Os estímulos eram formados por artigo + substantivo + adjetivo. Sendo o adjetivo sempre uma cor, por exemplo:

Conjunto 1: a borracha rosa, o lápis azul, a sandália preta, o short verde

Conjunto 2: a colher vermelha, o lápis azul, o pregador branco, a caneta verde, a tampa rosa

O programa de tato com autoclítico foi realizado de acordo com os passos descritos abaixo:

Passo 1 - Dica Modelo Vocal: O cuidador mostrava o item para criança e imediatamente emitia a resposta de tato com autoclítico e esperava até 3 segundos pela resposta. Por exemplo, "o peixe vermelho". 
Passo 2 - Espera de 3s + DMV: O cuidador apresentava o item e esperava 3 segundos pela resposta independente da criança. Se ela não ocorresse, ele emitia o tato com autoclítico e esperava até 3 segundos pela resposta.

Passo 3 - Tato com Autoclítico Independente: $\mathrm{O}$ cuidador apresentava o item e esperava 5 segundos pela resposta independente.

Passo 4 - Manutenção: Após aproximadamente um mês sem realização deste programa, o cuidador repetia o programa para verificar a manutenção.

Passo 5 - Refinamento de Controle de Estímulo (RCE): A criança deveria emitir o tato com autoclítico com uma pessoa diferente do cuidador. Esse passo foi realizado após o Passo 4, no mesmo dia.

As respostas corretas eram seguidas por elogios e brinquedos para todas as crianças. Em algumas sessões com Vítor foram utilizados comestíveis. Caso a criança não respondesse ou respondesse errado, era aplicado o procedimento de correção de erro, que será detalhado a seguir.

Os pais eram instruídos a realizar o programa, no mínimo, quatro vezes por semana. A duração do ensino variava de criança para criança, uma vez que, como mencionado anteriormente, elas realizavam outros programas concomitantemente, como "mando com autoclítico", "informações pessoais" e "intraverbal sim/não".

Alguns exemplos de como realizar o programa de modo incidental eram ensinados aos pais, mas nenhuma forma de controle deste ensino era realizada, nem era cobrado dos pais qualquer registro desse ensino incidental.

\section{Mudança de Passo}

Antes de começar os Passos 1 e 2 era realizada uma sondagem. Neste procedimento eram realizadas três tentativas. Caso a criança acertasse duas tentativas, o cuidador avançava para o Passo 3.

Para avançar o passo, a criança deveria ter mais de $90 \%$ de acertos em dois blocos consecutivos, ou $100 \%$ de respostas independentes em um bloco. Caso apresentasse menos de $75 \%$ de acertos, ela retornava ao passo anterior. Os cuidadores realizavam um bloco por dia.

O programa era realizado em blocos de 10 ou 20 tentativas de acordo com as características individuais das crianças. Os Passos 4 e 5 foram realizados com cinco tentativas.

\section{Correção de Erro}

A resposta era considerada errada caso a criança não respondesse dentro do tempo estipulado ou respondesse errado. Nesse caso, era aplicado um procedimento de correção de erro. Por exemplo, se a criança não emitisse o tato com autoclítico ou emitisse um tato não correspondente ao exigido, o cuidador retirava o item do campo visual da criança e olhava para o lado por 5 segundos, removendo atenção à criança. Após esse tempo, ele apresentava o item novamente e emitia a DMV e esperava a resposta ecóica da criança, de acordo com o passo. Respostas corretas em tentativas de correção com DMV não eram reforçadas: ao invés disso, se iniciava uma nova tentativa com o item sendo mais uma vez apresentado para criança. Se a criança errasse por três vezes consecutivas, para manter o engajamento da criança, o aplicador solicitava uma resposta já bem estabelecida no repertório da criança e reforçava sua resposta ao novo item com a apresentação de um reforçador de menor magnitude, ou seja, um reforçador de média preferência, de acordo com avaliações anteriores de preferência por reforçadores.

\section{RESULTADOS}

A Figura 1 apresenta a porcentagem de respostas independes de Luna com dois conjuntos de estímulo ao longo da Linha de Base, Passo 3 Independente, Passo 4 - Manutenção e Passo 5 - RCE.

Como pode ser observado na Figura 1, Luna começou o ensino do Conjunto1 no com $0 \%$ de respostas independentes, e atingiu $100 \%$ de respostas independentes no Passo 3, mantendo uma precisão de desempenho de $100 \%$ e $80 \%$ nos passos 4 e 5 , respectivamente.

O ensino de tato com o conjunto 2 iniciou no Passo 1 com $0 \%$ de respostas independentes. Luna obteve $100 \%$ de precisão de desempenho no Passo 3 e nos Passos 4 e 5 , realizados um mês após a fase de ensino, o desempenho foi de $75 \%$ em ambos, tanto na presença do cuidador (Passo 4), como na de outro ouvinte (refinamento de controle).

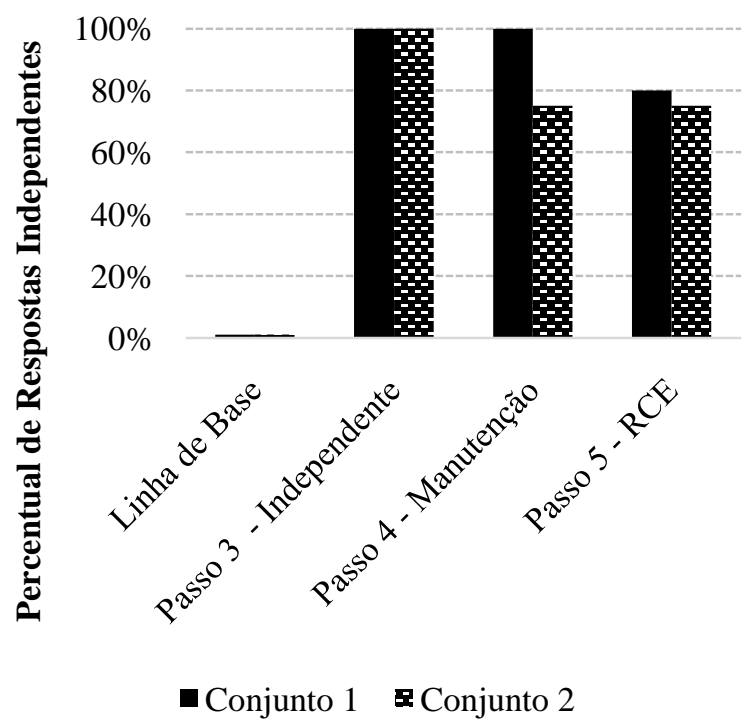

Figura 1. Percentual de respostas independentes na Linha de Base, Passo 3 - Independente, Passo 4 - Manutenção e Passo 5 RCE, no ensino de tato com autoclítico para Luna, com os conjuntos 1 e 2 .

Vítor iniciou o ensino de tato com os estímulos do Conjunto 1 em $33 \%$ de respostas independentes e alcançou $100 \%$ no Passo 3. O desempenho nos Passos 
4 e 5, de manutenção, foram de $75 \%$ e $60 \%$, respectivamente. $\mathrm{O}$ ensino com o Conjunto 2 também foi iniciado com $33 \%$ de respostas independentes chegando a $85 \%$ no Passo 3 . A precisão de desempenho nos Passos 4 e 5 foi de 60\%. Houve algumas dificuldades da cuidadora em relação a troca de passos nesse programa.

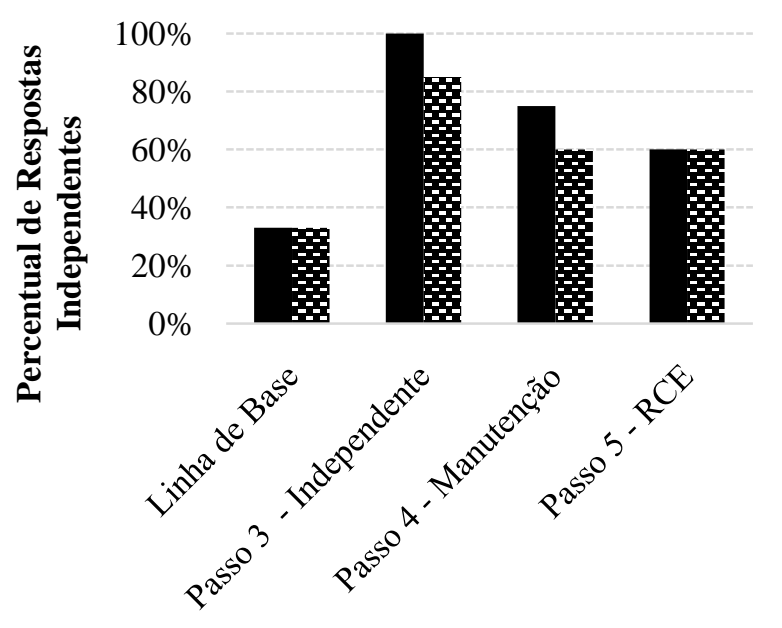

- Conjunto 1 conjunto 2

Figura 2. Percentual de respostas independentes na Linha de Base, Passo 3 - Independente, Passo 4 - Manutenção e Passo 5 - RCE, no ensino de tato com autoclítico para Victor, com os conjuntos 1 e 2 .

Haroldo foi a única criança a realizar treinos com três conjuntos de estímulos, tendo todos a partir do Passo 1. O Conjunto 1 iniciou com $8 \%$ de respostas independentes, chegou a $85 \%$ no Passo 3 e nos Passos 4 e 5 (um mês após a intervenção), a criança apresentou desempenhos de $80 \%$ e $100 \%$, respectivamente.

Com o Conjunto 2, Haroldo iniciou com $0 \%$ de respostas independentes, atingiu 90\% no Passo 3 e nos Passos 4 e 5, o desempenho também foi de $80 \%$ e $100 \%$.

Com o Conjunto 3, iniciou com $8 \%$, atingiu $100 \%$ de respostas independentes no Passo 3 e nos Passos 4 e 5, o desempenho foi mantido em $83 \%$.

Por fim, a Figura 4 mostra o percentual de acertos dos três participantes na Linha de Base, no Passo 3 e no Passo 5. É possível observar que Vítor, Haroldo e Luna não possuíam repertório independente de tato com autoclítico antes da intervenção dos cuidadores. Essa habilidade foi apresentada com mais de $90 \%$ de acertos para as três crianças ao completarem o Passo 3. Após um mês do término do ensino e com outras pessoas apresentando os estímulos (Passo 5), o percentual de acertos, considerando todos os conjuntos de estímulos, foi de $60 \%$ para Vitor, de $78 \%$ para Luna e de $94 \%$ para Haroldo.

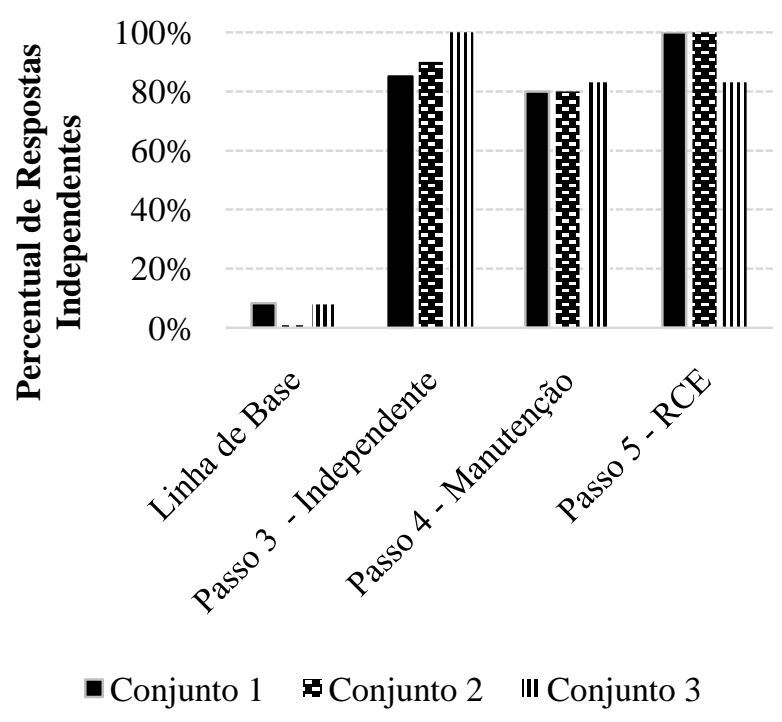

Figura 3. Percentual de respostas independentes na Linha de Base, Passo 3 - Independente, Passo 4 - Manutenção e Passo 5 $\mathrm{RCE}$, no ensino de tato com autoclítico para Haroldo, com os conjuntos 1 e 2 .

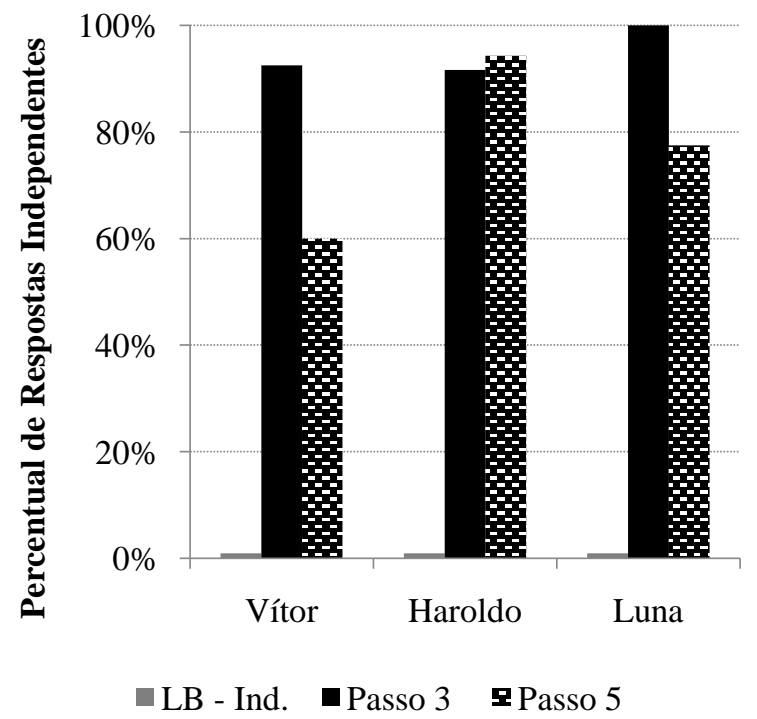

Figura 4. Percentual de acertos de Vítor, Haroldo e Luna na Linha de Base, no Passo 3 (independente) e no Passo 5 (Refinamento de Controle de Estímulo).

\section{DISCUSSÃO}

O objetivo deste trabalho foi propor e avaliar um programa de ensino de tato com autoclítico para crianças com diagnóstico de autismo, por meio da intervenção via cuidadores, bem como averiguar a manutenção desse repertório com o cuidador e com outras pessoas, um mês após o encerramento do programa. O ensino foi realizado usando dica modelo vocal (DMV) com e sem atraso. Os dados obtidos apontaram a aprendizagem deste repertório por todas as crianças, mostrando um aumento significativo do percentual de acertos em relação à linha de base. 
Como pode ser observado na Figura 4, Vítor, Luna e Haroldo mostraram aumento de precisão de desempenho, respectivamente, de $92 \%, 100 \%$ e $91 \%$ entre a linha de base (que foi de $0 \%$ para todos) e a conclusão do Passo 3. Além disso, a variação entre a linha de base e o último follow-up (Passo 5) foi de respectivamente $60 \%$, $78 \%, 94 \%$. Embora se possa sugerir que, em pesquisas futuras, a Linha de Base seja realizada com cada um dos estímulos usados no treino e não de modo geral como foi realizado, é possível afirmar que o procedimento adotado gerou aprendizagem com bons níveis de manutenção, um mês após a intervenção.

Esses dados indicam a efetividade de uma intervenção analítico comportamental via cuidadores, com o uso do procedimento de tentativa discreta, corroborando os dados de Lafasakis e Sturmey (2007) e ampliando a possibilidade de usar tentativa discreta para o ensino de repertórios verbais e não apenas motores, como foi investigado pelos referidos autores. Além disso, mostra a possibilidade do ensino de repertórios verbais, o que em pesquisas como de Crockett et al. (2007) não ocorreu com aumento significativo.

Os dados mostram, ainda, que o repertório de tato com autoclítico passou a ser emitido de forma independente após uma média de 2,5 Blocos para Vítor, 4,5 Blocos para Luna e 3,3 Blocos para Haroldo. Esses resultados constatam a eficácia do programa de ensino e contradizem a suposição de Crockett et al. (2007) de que seria necessário um grande número de sessões para o repertório melhorar, sendo passível de observação após meses ou anos. É importante, contudo, levar em consideração que o repertório almejado no presente estudo era o de tato com autoclítico, com crianças que já tateavam, enquanto em Crockett et al. (2007) o ensino foi de tato. Ambas as pesquisas ensinaram mais de um repertório ao mesmo tempo.

Além disso, embora para duas crianças, os resultados, após um mês sem intervenção, tenham sido inferiores aos resultados durante a fase de treino, o percentual de acertos ainda foi significativo, mostrando a manutenção do repertório adquirido mesmo sem a exposição diária ao programa, com Vitor apresentando $60 \%$ de acertos nessa fase, Haroldo $94 \%$ e Luna $78 \%$. Entretanto, um teste de follow-up, após um período maior de tempo, como o realizado por Smith et al. (2000), seria importante para investigar se há uma tendência decrescente no desempenho da criança.

Outro ponto que deve ser investigado em pesquisas futuras é a variável que leva ao bom desempenho de Haroldo nos Passo 4 e 5 (ver Figura 3) quando comparado a Vítor e Luna. Uma hipótese é que esse desempenho esteja relacionado à operação motivadora dos estímulos como colocado por Davis et al. (2012) e ao contato que a criança teve com aquele estímulo durante o tempo sem treino. Neste caso específico de Haroldo, o que está sendo nomeado aqui como tato poderia ser mais propriamente nomeado de mando. Essa hipótese poderia ser investigada analisando a preferência da criança pelos estímulos utilizados na fase de ensino (com o mesmo procedimento usado para identificar reforçadores), acrescida de um período de observação em que a criança pudesse brincar livremente com os estímulos utilizados para o ensino, apresentados simultaneamente a outros brinquedos.

Ao observar os dados de Haroldo (ver Figura 3), outro dado que destoa em relação às demais crianças é que seu desempenho no Passo 5 foi superior ao seu desempenho no Passo 4, chegando a atingir $100 \%$ com os Conjuntos 1 e 2. É também possível que o desempenho no Passo 4 tenha sido inferior devido às respostas de birra da criança na presença da cuidadora, o que possivelmente prejudicou o desempenho com a mesma.

Outra questão interessante é que, embora os cuidadores tenham aplicado o procedimento de tentativa discreta corretamente, eles apresentaram algumas dificuldades para seguir o critério exato de mudança de passo, cometendo alguns erros. Dado similar foi encontrado por Smith et al. (2000) que apontam que os cuidadores não aprendem a aplicar o procedimento com a mesma precisão de um profissional. Contudo, no presente estudo, essa imprecisão não pareceu afetar o desempenho da criança que apresentou uma linha crescente de precisão. Em pesquisas futuras seria importante estabelecer medidas específicas para acompanhar a aprendizagem dos cuidadores e sua influência no desempenho das crianças, como as utilizadas por Lafasakis e Sturmey (2007) e Crockett et al. (2007).

A transferência de função do repertório de tato para o repertório de mando (cf. Finn et al., 2012) poderá ser investigada em pesquisas futuras. Além disso, considerando a própria definição estrita de repertório autoclítico, será importante, em pesquisas futuras, observar a ocorrência desse tipo de repertório com novos estímulos, de forma a se garantir que o repertório seja de fato autoclítico, ou seja, repertório verbal sob controle do próprio repertório verbal do falante. A resposta verbal da criança "o peixe vermelho", por exemplo, se sob controle exclusivamente do estímulo antecedente não verbal (o objeto peixe), não caracterizará a função de tato com autoclítico, mas apenas de um tato com múltiplos componentes. A modificação/especificação de tatos pela adição do autoclítico "vermelho" deveria aparecer em outros contextos com outros estímulos, mostrando que o autoclítico "vermelho" é controlado pelo próprio repertório verbal do falante e não meramente um componente do tato "o peixe vermelho". É importante relatar aqui que alguns cuidadores observaram de forma assistemática a emergência de novos tatos com autoclíticos em suas crianças. Esse tipo de ocorrência precisa ser melhor registrada e investigada em pesquisas futuras desta natureza.

Por fim, é importante ressaltar que a pesquisa relatada no presente estudo, abre perspectivas promissoras para se buscar formas de disseminação, com qualidade, da análise comportamental aplicada ao autismo no Brasil. Iniciativas como esta estão em andamento no mesmo e em outros laboratórios no Brasil (e.g., Centro para o Autismo e Inclusão Social, CAIS-USP, sob a coordenação da Profa. Martha Hübner, e Instituto Lahmiei/UFSCar, sob a coordenação do Prof. Celso Goyos). 


\section{REFERÊNCIAS}

American Psychiatric Association. (2013). Diagnostic and statistical manual of mental disorders (5th ed.). Arlington, VA: American Psychiatric Publishing.

Borba, M. M. C. (2014). Intervenção ao autismo via cuidadores. Tese de Doutorado, Programa de PósGraduação em Teoria e Pesquisa do Comportamento, Universidade Federal do Pará, Belém: PA. http://www.ufpa.br/ppgtpc

Brino, A. L. F., \& Souza, C. B. A. (2005). Comportamento verbal: uma análise da abordagem skineriana e das extensões explicativas de Stemmer, Hayes e Sidman. Interação em Psicologia, 9, 251230.

Carr, J. E., Nicolson A. C., \& Higbee T.S. (2000). Evaluation of a brief multiple-stimulus preference assessment in a naturalistic context. Journal of Applied Behavior Analysis, 33, 353-357.

Cohen, H., Amerine-Dickens, M., \& Smith, T. (2006). Early intensive behavioral treatment: Replication of the UCLA Model in a community setting. Journal of Developmental and Behavioral Pediatrics, 27, 51455155

Crockett, J., Fleming, R. K., Doepke, K., \& Stevens, J. (2007). Parent training: Acquisition and generalization of discrete trials teaching skills with parents of children with autism. Research in Developmental Disabilities, 28(1), 23-36.

Davis, B. J., Kahng, S., \& Coryat, K. (2012). Manipulating motivating operations to facilitate the emergence of mands for a child with autism. The Analysis of Verbal Behavior, 28(1), 145-50.

DeLeon, I., \& Iwata, B. (1996). Evaluation of a multiplestimulus presentation format for assessing reinforcer preferences. Journal of Applied Behavior Analysis 29, 519-533.

Eikeseth, S., Smith T., Jahr E., \& Eldevik S. (2002). Intensive behavioral treatment at school for 4- to 7year-old children with autism. A 1-year comparison controlled study. Behavior Modification, 26, 49-68.

Eikeseth, S., Klintwall, L., Jahr, E., \& Karlsson, P. (2012). Outcome for children with autism receiving early and intensive behavioral intervention in mainstream preschool and kindergarten settings. Research in Autism Spectrum Disorders, 6, 829-835.

Eldevik, S., Hastings, R. P., Jahr, E., \& Hughes, J. C. (2012). Outcomes of Behavioral Intervention for Children with Autism in Mainstream Pre-School Settings. Journal of Autism and Developmental Disorders, 42, 210-220.

Faggiani, R. B. (2014). Análise de componentes de um tutorial computadorizado para ensinar a realização de tentativas discretas. Tese de doutorado, Programa de Pós-Graduação em Psicologia Experimental, Universidade de São Paulo. São Paulo: SP.

Finn, H., Miguel, C. F., \& Ahearn, W. H. (2012). The emergence of untrained mands and tacts in children diagnosed with autism. Journal of Applied Behavior Analysis, 45, 265-280.
Gillett, J. N., \& LeBlanc, A. L. (2007). Parentimplemented natural language paradigm to increase language and play in children with autism. Research in Autism Spectrum Disorders, 1, 247-255.

Guzinski, E. M., Cihon, T. M., \& Eshleman, J. (2012). The effects of tact training on stereotypic vocalizations in children with autism. The Analysis of Verbal Behavior, 28(1), 101-10.

Hsieh, H., Wilder, D. A., \& Abellon, O. E. (2011). The effects of training on caregiver implementation of incidental teaching. Journal of Applied Behavior Analysis, 44, 199-203.

Kaplan, H. I., \& Sadock, B. J. (2007). Compêndio de Psiquiatria (9a ed.). (C. Dornelles, trad.). Porto Alegre: Artmed.

Keller, F. (1999). Adeus mestre. Revista Brasileira de Terapia Comportamental e Congnitiva, 1, 9-21.

Kodak, T., \& Clements, A. (2009). Acquisition of mands and tacts with concurrent echoic training. Journal of Applied Behavior Analysis, 42, 839-843.

Lafasakis, M., \& Sturmey, P. (2007) Training parent implementation of discrete-trial teaching: Effects on generalization of parent teaching and child correct responding. Journal of Applied Behavior Analysis, 40, 685-689.

Lovaas, 0. I. (1987). Behavioral treatment and normal intellectual and educational functioning in autistic children. Journal of Consulting and Clinical Psychology, 55, 3-9.

Lovaas, O. I. (2003). Teaching individuals with developmental delays: Basic intervention techniques. Austin, TX: Pro-Ed.

Matson, M. L., Mahan, S., \& Matson, J. L. (2009). Parent training: A review of methods for children with autism spectrum disorders. Research in Autism Spectrum Disorders, 3, 868-875.

McConachie, H., Phil, M., \& Diggle, T. (2007). Parent implemented early intervention for young children with autism spectrum disorder: A systematic review. Journal of Evaluation in Clinical Practice, 13, 120 129.

Sallows, G. O., \& Graupner, T. D. (2005). Intensive behavioral treatment for children with autism: Fouryear outcome and predictors. American Journal on Mental Retardation, 6, 417-438.

Skinner, B. F. (1992). Verbal behavior. Englewood Cliffs, NJ: Prentice Hall. (Publicado originalmente em 1957).

Smith, T., Buch, G. A., \& Gamby, T. E. (2000). Parent directed, intensive early intervention for children with pervasive developmental disorder. Research in Developmental Disabilities, 21, 297-309.

Smith, T., Eikeseth, S., Klevstrand, M., \& Lovaas, O. I. (1997). Intensive behavioral treatment for preschoolers with severe mental retardation and pervasive developmental disorder. American Journal on Mental Retardation, 102, 238-249.

Sundberg, M. L., Endicott, K., \& Eigenheer, P. (2000). The use of intraverbal prompts to teach tacts to 
children with autism. The Analysis of Verbal Behavior, 17, 89-104.

Valentino, A. L., \& Shillingsburg, M. A. (2011). Acquisition of mands, tacts, and intraverbals through sign exposure in an individual with autism. The Analysis of Verbal Behavior, 27, 95-101.
Wolery, M., \& Garfinkle, A. N. (2002). Measures in intervention research with young children who have autism. Journal of Autism and Developmental Disorders, 32(5), 463-478. 